\title{
In Vivo Estimation of Osteogenesis by Bone Marrow Cells in a Bi-Phasic Scaffold and in Each of Its Components
}

\author{
Masataka Yoshikawa*, Hideyuki Kakigi, Ayano Miyamoto, Sadaomi Sugimoto, Keisuke Nakai, \\ Hideaki Ikenaga, Takeshi Inamoto, Hiroshi Maeda
}

Department of Endodontics, Osaka Dental University, Osaka, Japan

Email: *yosikawa@cc.osaka-dent.ac.jp

How to cite this paper: Yoshikawa, M., Kakigi, H., Miyamoto, A., Sugimoto, S., Nakai, K., Ikenaga, H., Inamoto, T. and Maeda, H. (2016) In Vivo Estimation of Osteogenesis by Bone Marrow Cells in a BiPhasic Scaffold and in Each of Its Components. J. Biomedical Science and Engineering, 9, 501-514.

http://dx.doi.org/10.4236/jbise.2016.911045

Received: September 1, 2016

Accepted: October 23, 2016

Published: October 26, 2016

Copyright (c) 2016 by authors and Scientific Research Publishing Inc.

This work is licensed under the Creative Commons Attribution International License (CC BY 4.0).

http://creativecommons.org/licenses/by/4.0/

\begin{abstract}
A bi-phasic scaffold consisting of a columnar formaldehyde-acetalized polyvinyl alcohol (PVF) sponge and a cylindrical porous hydroxyapatite (HA) with a hollow center was devised. Rat bone marrow cells (rBMCs) were seeded into the sponge placed in the hollow center of the cylindrical porous HA. The bi-phasic scaffold, a cylindrical porous HA and a PVF sponge separated from a bi-phasic scaffold after rBMC seeding, and a PVF sponge without rBMCs as a negative control, were implanted for 6 weeks into rat dorsal subcutaneous tissue. In each construct, bone formation was examined histologically and osteocalcin was measured immunochemically. Bone formation was observed in the bi-phasic scaffold and also in the cylindrical porous HA isolated from the bi-phasic scaffold. A significant difference in the quantity of osteocalcin was observed between the bi-phasic scaffold and the isolated cylindrical porous HA. No bone formation was found in the isolated PVF sponge. The bi-phasic scaffold as an outer layer of the scaffold seemed to inhibit the outflow of rBMCs from the PVF sponge. This type of bi-phasic scaffold may have two specific characteristics: Attachment of cells both in PVF sponge and cylindrical porous HA.
\end{abstract}

\section{Keywords}

Bi-Phasic Scaffold, Hydroxyapatite, Polyvinyl Alcohol Sponge, Bone Formation, In Vivo

\section{Introduction}

Pluripotent stem cells are widely considered to contribute to tooth regeneration. However, in order to use these cells for tooth regeneration in dentistry, additional studies 
are necessary. Currently, the implantation of a pin or blade made from metal, such as titanium, has been adopted as the conventional method for replacing a missing tooth [1] [2] [3]. The use of a scaffold for tooth regeneration is essential because the structure of a tooth is three-dimensional. It has been reported that porous hydroxyapatite (HA) is suitable as a scaffold for bone regeneration [4] [5]. The HA, with excellent histocompatibility, is valid as a scaffold because its constitution is similar to bone and tooth. Therefore, HA may be suitable as a scaffold for regeneration of a missing or partially defective tooth. It has been reported that porous HA is suitable as a scaffold for bone regeneration [4] [5]. The HA, with excellent histocompatibility, is valid as a scaffold because its constitution is similar to bone and tooth. Therefore, HA may be suitable as a scaffold for regeneration of a missing or partially defective tooth.

Many studies have already been performed regarding promotion of bone regeneration with a HA scaffold and have reported that a large number of mesenchymal stem cells would be needed to form a sufficient amount of bone in a scaffold [6] [7] [8]. Therefore, the factors required for bone regeneration in scaffolds must be elucidated to promote the proliferation of stem cells and ensure their differentiation into osteoblasts. Yoshikawa et al. confirmed in an in vivo study that, after seeding rat bone marrow cells (rBMCs), bone was formed conspicuously in many pores in a cylindrical porous HA scaffold with a hollow center, but not in the center area of a columnar porous HA without a hollow center [9]. It was also reported that nutrition for the rBMCs in the pores may be supplied through the hollow center of the scaffold. Furthermore, adhesion of the rBMCs to the pore wall of the scaffold can be effectively encouraged by coating the scaffold with chemical agents [10] [11].

Teeth are mainly composed of the hard tissues, namely, dentin, enamel and cementum. Dentin surrounds the dental pulp, and is covered by enamel in the crown and cementum in the root. A bi-phasic scaffold consisting of cylindrical porous HA with a hollow center and a columnar shaped spongecan closely reproduce the structure of a tooth. In this study, a columnar shaped formaldehyde-acetalized polyvinyl alcohol (PVF) sponge was placed in the hollow center of the scaffold to reproduce the pulp cavity. However, it was reported that if the sponge was used as the scaffold, adhesion to the fine construction of the material would be difficult for stem cells [12]. Thus, in a previous study, to improve the cell adhesion properties, a PVF sponge was coated with tryptophan or lysine in the bi-phasic scaffold and in vivo osteogenesis was measured with rat bone marrow cells [13]. A high level of osteogenesis in the sponge of the bi-phasic scaffold was observed. However, as previously reported, little bone was formed in the chemically coated PVF sponge [14]. In this in vivo study, before subcutaneous implantation, rBMCs from the femora of male Fischer 344 rats were seeded into the columnar sponge in the hollow center of the bi-phasic scaffold composed of cylindrical porous HA. Next, a bi-phasic scaffold with rBMCs, a scaffold where the cylindrical porous HA was removed after rBMC seeding, and a PVF sponge with and without rBMCs were implanted into the dorsal subcutaneous tissue of syngeneic ratsin order to examine bone formation in each material. These materials were resected after 
an experimental period from the rat subcutaneous tissue for quantitative analysis of alkaline phosphatase (ALP) and osteocalcin. The levels of ALP and osteocalcin correlating with bone formation were immunochemically and biochemically measured in each material.

The purpose of this study was to examine bone formation in the newly devised biphasic scaffold in vivo. In particular, the potential for bone formation in the bi-phasic scaffold by seeded rBMCs in the PVF sponge with no chemical modification was examined.

\section{Materials and Methods}

\subsection{Preparation of Experimental Bi-Phasic Scaffolds}

A bi-phasic scaffold composed of cylindrical porous HA with a hollow center and a columnar PVF sponge was devised and used as a scaffold in this in vivo study. The materials were sterilized in ethylene oxide gas before experimental use.

The cylindrical porous HA (Figure 1(a)) was custom-made for this study by Hoya Technosurgical Company (Tokyo, Japan) in accordance with our design. Disk-shaped porous HA scaffolds with the same properties as ones used in this study are commercially available (Hoya Technosurgical Company). The details of the structure of the cylindrical porous HA were described in previous reports [9]. In brief, the cylindrical porous HA was $8 \mathrm{~mm}$ in diameter and $10 \mathrm{~mm}$ in height, with a hollow center measuring $5 \mathrm{~mm}$ in diameter. The total porosity of the structure was $55 \%$. The diameter of each aperture on the surface of the cylindrical porous HA was approximately $100-300$ $\mu \mathrm{m}$. The aperture diameter between interconnected pores was approximately $50-300$ $\mu \mathrm{m}$.

The sponge was made by acetalization of polyvinyl alcohol with formaldehyde (PVF sponge). The sponge is commercially available. In this study, a sheet of PVF sponge was kindly donated by Aion Co., Ltd. (Osaka, Japan). PVF sponges were cut as a column from the PVF sponge sheet. The column of PVF sponge used as a scaffold in this study was $5 \mathrm{~mm}$ in diameter and $10 \mathrm{~mm}$ in height. A scanning electron microscopic image of
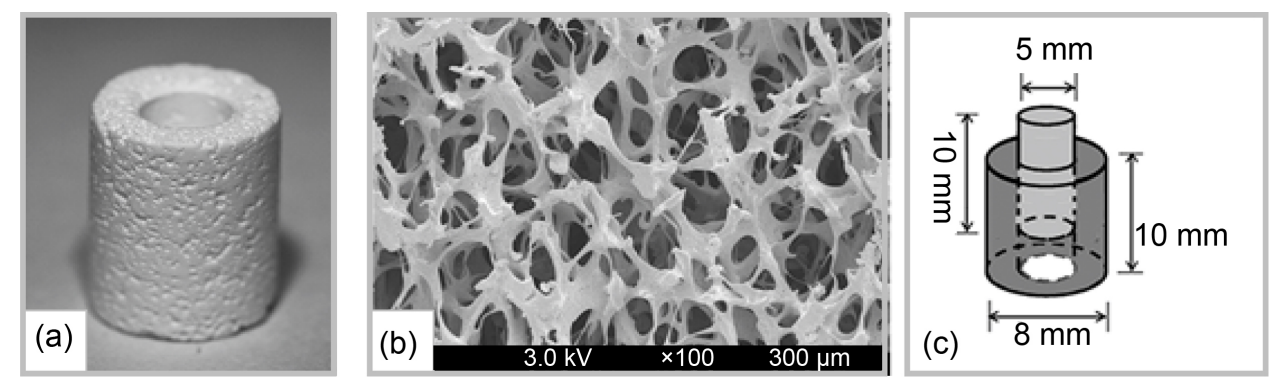

Figure 1. (a) A macro-photograph of the circular porous HA. The aperture of the hollow center with a diameter of $5 \mathrm{~mm}$ is shown in the upper transverse plane. A large number of pore apertures are seen on the surface of the circular porous HA. (b) A scanning electron microscope image of the formaldehyde-acetalized PVF sponge. (c) An illustration of the devised bi-phasic scaffold. The height and diameter of the circular porous HA and PVF sponge are indicated. The sponge would be inserted completely in the hollow center of the circular porous HA. 
the PVF sponge is shown in (Figure $1(\mathrm{~b})$ ). The pore size was $130 \mu \mathrm{m}$ on average. The sponge was inserted into the hollow center of the cylindrical porous HA, as shown in the illustration (Figure 1(c)).

\subsection{Experimental Animals}

This study was performed in accordance with the Guidelines for Animal Experimentation of Osaka Dental University. Regarding the use and care of the animals, the Animal Welfare Committee of Osaka Dental University approved the experimental procedures. Male Fischer 344 rats (Japan SLC, Inc., Hamamatsu, Japan) were used. These rats were kept in standard rat cages with freeaccess to dry pellets and water, with unrestricted movement at all times during feeding. All animal surgical procedures in this study were performed under general anesthesia by the intra-peritoneal injection of sodium pentobarbital (DS Pharma Biomedical Co., Ltd., Osaka, Japan) at a dosage of $4 \mathrm{mg}$ per $100 \mathrm{~g}$ of body weight.

\subsection{Preparation of rBMC Suspension}

rBMCs were taken from the femoral shafts of 6-week-old male Fischer 344 rats after euthanasia of the rats by intra-peritoneal injection of an excessive dose of sodiumpentobarbital (DS Pharma Biomedical Co., Ltd, Osaka, Japan). The cells were flushedout using $10 \mathrm{ml}$ of culture medium expelled from a syringe with a 21-gauge needle. Primary culture of the cells was performed for 1 week in a cell culture flask (T-75; BD Biosciences, MA, USA) containing minimum essential medium (MEM; Nacalai Tesque, Inc., Kyoto, Japan) supplemented with 15\% fetal bovine serum (FBS; SAFC Biosciences Inc., KC, USA) and antibiotics ( $100 \mathrm{U} / \mathrm{ml}$ penicillin, $100 \mathrm{mg} / \mathrm{ml}$ streptomycin and 0.25 $\mathrm{mg} / \mathrm{ml}$ amphotericin B; Sigma-Aldrich Co., MO, USA). The medium was changed two times. After primary culture, rBMCs in the T-75 culture flask were washed three times using phosphate-buffered solution without $\mathrm{Ca}^{2+}$ and $\mathrm{Mg}^{2+}$ (PBS (-); NacalaiTesque Inc.) and the cells were isolated from the bottom of the T-75 flask with trypsin-EDTA solution $(0.5 \mathrm{mg} / \mathrm{ml}$ trypsin and $0.53 \mu \mathrm{M}$ EDTA; Nacalai Tesque Inc.) to prepare the bone marrow cell suspension. Harvested cells were re-suspended in culture medium at a concentration of $1 \times 10^{7} \mathrm{cells} / \mathrm{ml}$ in preparation for in vivo examination.

\subsection{Seeding of rBMCs in a Scaffold and Dorsal Subcutaneous Implantation of the Scaffolds}

To seed $1.5 \times 10^{6} \mathrm{rBMCs}$ in the PVF sponge in the bi-phasic scaffold, $150 \mu \mathrm{l}$ of the cell suspension $\left(1 \times 10^{7}\right.$ cells $\left./ \mathrm{ml}\right)$ was dropped on the sponge. After 2 hours of incubation at $37^{\circ} \mathrm{C}$ in $5 \% \mathrm{CO}_{2}$ and $95 \%$ relative humidity, the sponge with the rBMCs in the hollow center was removed from six bi-phasic complexes.

After general anesthesia by intra-peritoneal injection of sodium pentobarbital at a dosage of $4 \mathrm{mg}$ per $100 \mathrm{~g}$ of body weight, the backs of the syngeneic rats were shaved and disinfected with povidone iodine solution (ISODINE ${ }^{\circledR}$ solution $10 \%$; Meiji Seika Pharma Co., Ltd., Tokyo, Japan). On the back of each rat, two subcutaneous pockets 
were made on each side of the spinal column. In the left pocket, a bi-phasic scaffold with a PVF sponge containing rBMCs or a cylindrical porous HA separated from the bi-phasic scaffold after rBMC seeding was inserted. In the right pocket, a withdrawn PVF sponge from a bi-phasic scaffold after rBMC seeding or a sponge with no rBMC seeding was inserted. The number per a sort of materials prepared for implantation was six respectively. The back incisions for the pockets were sutured and covered with adhesive (Aron Alpha ${ }^{\circledR}$; Toagosei Co., Ltd., Tokyo, Japan). After euthanasia of the rats by intra-peritoneal injection of an excess dose of sodium pentobarbital, the implanted materials were removed from the dorsal subcutaneous tissue 6-weeks postoperatively.

\subsection{Histological Examination}

Half of each implanted material removed from the dorsal subcutaneous tissue at 6weeks postoperative was used for histological examination. The materials were fixed in $10 \%$ buffered formalin solution for 48 hours. The bi-phasic scaffolds and the cylindrical porous HA separated from the bi-phasic scaffolds were decalcified for 3 weeks in $10 \%$ formic acid. The PVF sponges were also decalcified in $10 \%$ formic acid solution for 24 hours. The materials were then permeated with xylene for embedding in paraffin after dehydration in ethanol. The paraffin-embedded samples were serially cut into $8-\mu \mathrm{m}$ thick sections. These sections were stained with hematoxylin-eosin or toluidine blue dye, alternately for histological examination under an optical microscope.

\subsection{Biochemical Analysis of Alkaline Phosphatase and Immunochemical Analysis of Osteocalcin for Bone Formation in Each Scaffold}

The other halves of the implanted materials were used for measurement of the ALP level biochemically and for quantitative analysis of osteocalcin immunochemically. After removal of the implanted materials from the subcutaneous tissue, they were immediately frozen in liquid nitrogen. The materials were then crushed and homogenized using a Mixer Mill ${ }^{\circledR}$ (MM301; Verder Scientific Co., Ltd., Tokyo, Japan) in $1 \mathrm{ml}$ of a 10-fold concentration of TNE buffer solution ( $\mathrm{pH}$ 7.4; $10 \mathrm{mM}$ Tris-HCl, $1 \mathrm{mM}$ EDTA, $100 \mathrm{mM} \mathrm{NaCl}$ ). The homogenized samples were sonicated (BIORUPTOR UCW-201; Tosho Denki Co., Ltd., Yokohama, Japan) for 30 seconds at $3^{\circ} \mathrm{C}$. The emulsified sample was passed through a column (PD-10 desalting column; GE Healthcare UK Ltd., Buckinghamshire, UK) to collect osteocalcin adhering to the cylindrical porous HA. For quantitative analysis of osteocalcin, a 96-well micro-plate (Rat osteocalcin ELISA kit DS $^{\circledR}$; DS Pharma Biomedical Co., Ltd.) was used. The bottom of each well was coated with anti-rat osteocalcin antibody. The desalted supernatants were respectively pouredinto each well. Peroxidase-conjugated anti-rat osteocalcin polyclonal antibody was added to each well. An equivalent mixture of peroxidase substrate and aqueous hydrogen peroxide was also added and incubated at room temperature in the dark for 30 minutes. Absorbance at $450 \mathrm{~nm}$ was measured for the samples using a spectrophotometer (Spectra Max M5; Molecular Devices Corporation Japan, Tokyo, Japan). Next, 
each sample was centrifuged for 1 minute at $16,000 \times \mathrm{g}$ to measure the quantity of ALP in the scaffolds biochemically. The supernatant was reacted at $37^{\circ} \mathrm{C}$ for 30 minutes with p-nitro-phenylphosphate (Zymed Laboratories Inc., CA, USA) as a substrate. Absorbance of the reactant was measured at $405 \mathrm{~nm}$. The level of ALP activity is presented per scaffold as $\mu \mathrm{M}$ of $p$-nitrophenol released after 30 minutes of incubation at $37^{\circ} \mathrm{C}$.

Data are presented as the mean \pm standard deviation. Statistical comparisons between the mean values in implanted scaffolds were performed using two-way unrepeated ANOVA followed by post hoc analysis using Tukey-Kramer's test. Differences of $p<0.01$ were considered significant.

\section{Results}

\subsection{Histological Findings of Subcutaneously Implanted Materials}

In each bi-phasic scaffold composed of cylindrical porous HA and rMBC-seeded PVF sponge before implantation, newly formed bone was observed conspicuously in both components (Figure 2(a) and Figure 2(b)). Bone formation was recognized by representative optical microscope images after subcutaneous implantation of the cylindrical porous HA that had been separated with the sponge from the bi-phasic scaffold (Figure 3(a) and Figure 3(b)). Bone was formed in many of pores of the cylindrical porous HA, from which the rBMC-seeded PVF sponge had been separated before implantation. In the hollow center of the separated cylindrical porous HA, necrotized connective tissue was observed. However, no bone formation was observed in rBMC-seeded sponges that were removed from the bi-phasic scaffolds before implantation (Figure 4). Only connective tissue was observed in the spaces of the filamentous structure in the sponges. Sponges without rBMC seeding, as negative control, showed no bone formation (Figure 5). Fibrous connective tissue was observed in the spaces of the filamentous structure in the sponge.

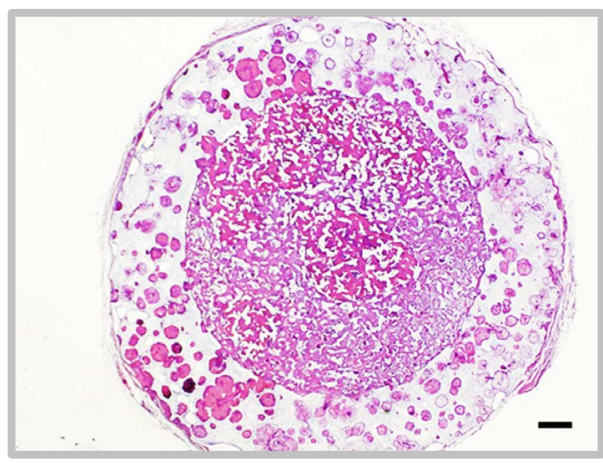

(a)

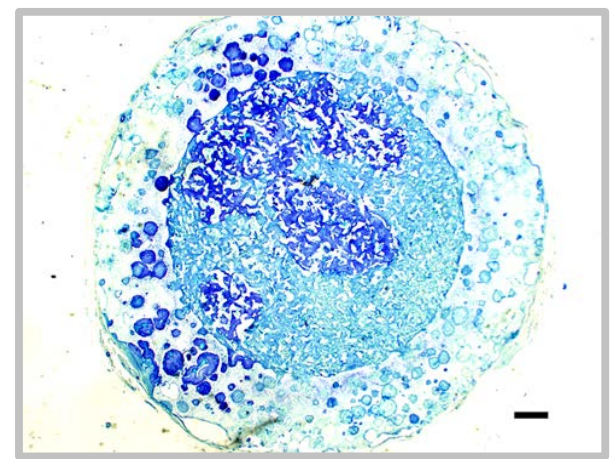

(b)

Figure 2. Optical microscope images of a histological section of the bi-phasic scaffold that was implanted subcutaneously for 6 weeks with seeded rat bone marrow cells in the formaldehyde-acetalized polyvinyl alcohol sponge (Bar: $500 \mu \mathrm{m}$ ). (a) Bone was found in part of the formaldehyde-acetalized polyvinyl alcohol sponge. Bone formation was also seen in the hydroxyapatite around the sponge (Hematoxylin and eosin staining). (b) The presence of bone in the bi-phasic scaffold is shown by toluidine blue dye staining. 


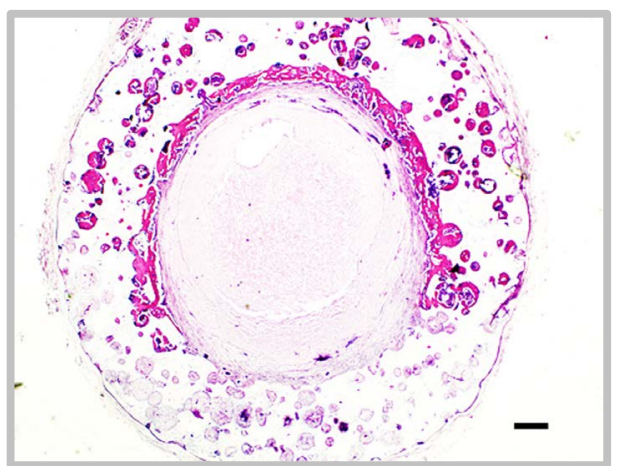

(a)

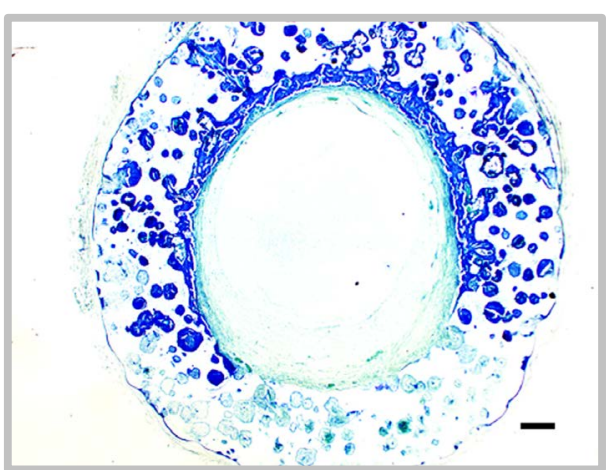

(b)

Figure 3. Optical microscope images after 6 weeks of subcutaneous implantation of circular porous hydroxyapatite that had been separated from the rat bone marrow cell-seeded formaldehyde-acetalized polyvinyl alcohol sponge (Bar: $500 \mu \mathrm{m}$ ). (a) Bone formation was found in many of the pores. In the hollow center, necrotized connective tissue was observed. (Hematoxylin and eosin staining). (b) The presence of bone in the bi-phasic scaffold was clearly shown by toluidine blue dye staining.

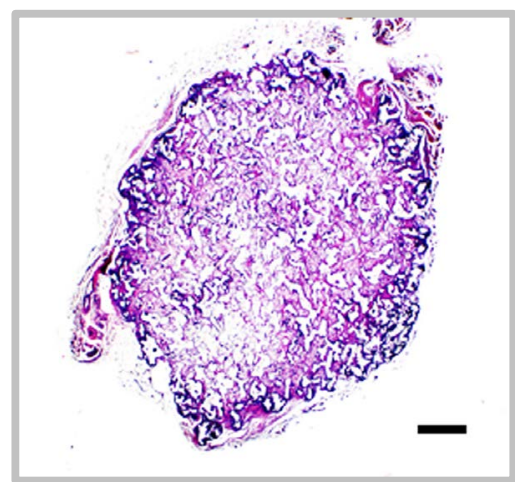

Figure 4. The sponge component, which was seeded with rat bone marrow cells then removed from the bi-phasic scaffold before implantation, showed no bone formation. Only connective tissue was observed in the spaces of the filamentous structure in the formaldehyde-acetalized polyvinyl alcohol sponge. (Bar: $500 \mu \mathrm{m}$ ).

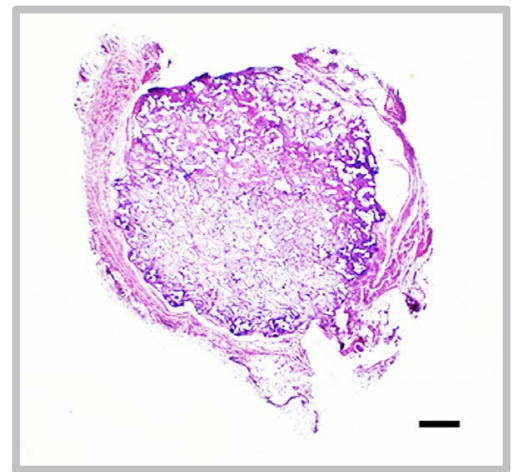

Figure 5. Optical microscope image after 6 weeks of subcutaneous implantation of formaldehyde-acetalized polyvinyl alcohol (PVF) sponge without seeding of rat bone marrow cells. No bone formation was seen in the PVF sponge. Fibrous connective tissue was observed in the spaces of the filamentous structure in the PVF sponge. (Bar: $500 \mu \mathrm{m}$ ). 


\subsection{Biochemical Analysis of Alkaline Phosphatase and Immunochemical Analysis of Osteocalcin in Each Implanted Material}

The measured quantity of ALP in each implanted material is shown in Figure 6. The measured mean values of ALP in each material were $827 \mu \mathrm{M}$ in the bi-phasic scaffold with a rBMC-seeded PVF sponge component, $16 \mu \mathrm{M}$ in the PVF sponge with rBMC seeding before separation from the bi-phasic scaffold, $926 \mu \mathrm{M}$ in the cylindrical porous HA as the bi-phasic scaffold component separated from the rBMC-seeded sponge and $15 \mu \mathrm{M}$ in the PVF sponge without rBMCs. An extremely small amount of ALP was detected in the sponges. There was a significant difference in this regard between the PVF sponges with or without rBMC seeding and the bi-phasic scaffold or the cylindrical porous HA. There was no significant difference in ALP quantity between the bi-phasic scaffold and the cylindrical porous HA.

The quantity of osteocalcin in each implanted material is shown in Figure 7. A higher quantity of osteocalcin was observed in the bi-phasic scaffold compared with in the cylindrical porous HA. The average osteocalcin quantity of the bi-phasic scaffold was $2.9 \mu \mathrm{g}$, whereas that of the separated cylindrical porous HA with rBMCs was $1.7 \mu \mathrm{g}$. The amount of osteocalcin in the bi-phasic scaffold was significantly different from that in the cylindrical porous HA. Separated sponges showed lower quantities of osteocalcin.

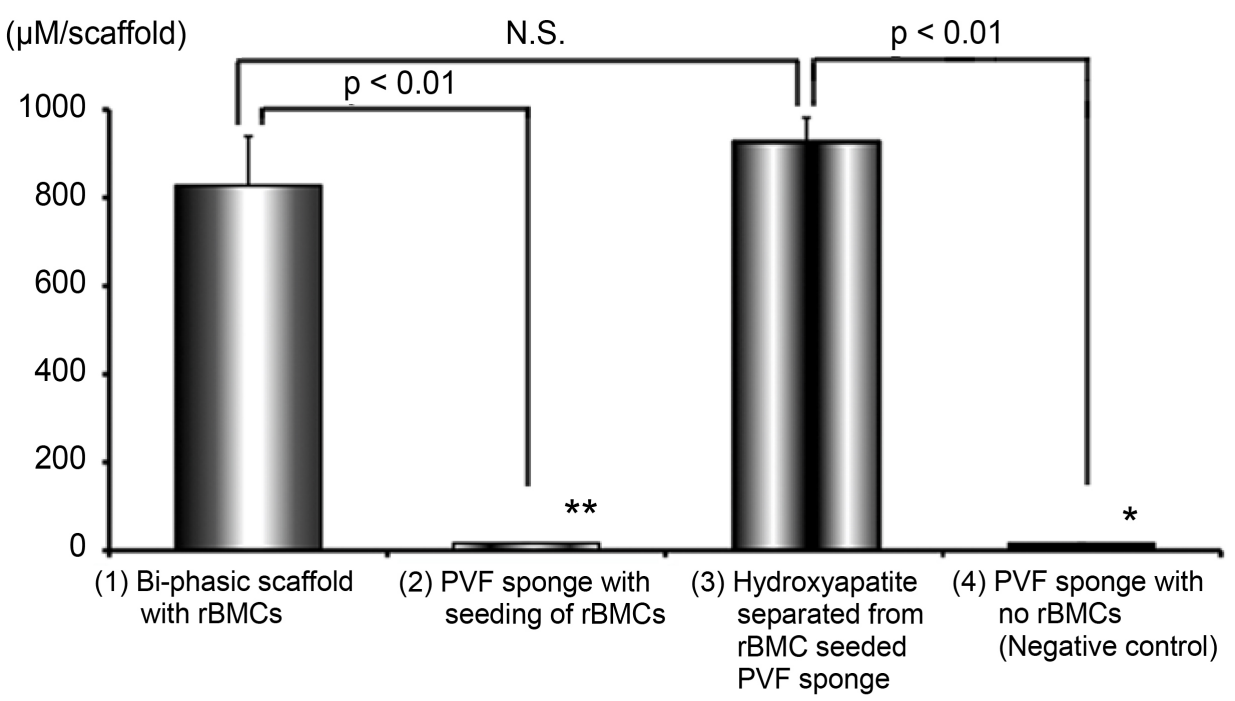

Figure 6. ALP in the bi-phasic scaffold showed no significant difference from that in the circular porous hydroxyapatite. Amount of alkaline phosphatase (ALP) measured in each material that had been implanted subcutaneously for 6 weeks. 1) Bi-phasic scaffold with rat bone marrow cells (rBMCs): A bi-phasic scaffold composed of circular porous hydroxyapatite and formaldehyde-acetalized polyvinyl alcohol (PVF) sponge with rBMCs; 2) PVF sponge with seeding of rBMCs: The PVF sponge after seeded with rBMCs was removed from the bi-phasic scaffold before implantation; 3) Hydroxyapatite separated from rBMCs seeded PVF sponge: Circular porous hydroxyapatite separated from the bi-phasic scaffold after seeding of rBMCs in the PVF sponge; 4) PVF sponge with no rBMCs: Negative control ${ }^{\star \star}$ vs. ${ }^{\star}$ : N.S. 


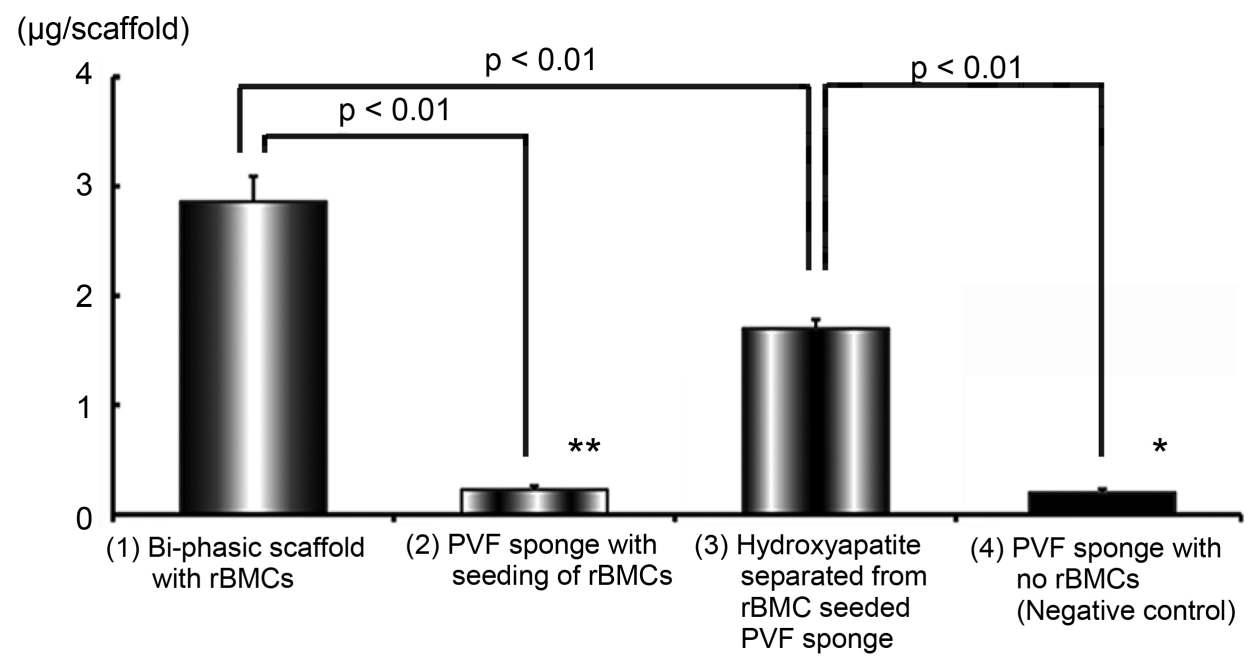

Figure 7. The quantity of osteocalcin differed significantly between the bi-phasic scaffold composed of hydroxyapatite and the rat bone marrow cell-containing formaldehyde-acetalized polyvinyl alcohol (PVF) sponge. Amount of osteocalcin measured in each material that had been implanted subcutaneously for 6 weeks. 1) Bi-phasic scaffold with rat bone marrow cells (rBMCs): A bi-phasic scaffold composed of circular porous hydroxyapatite and a formaldehyde-acetalized polyvinyl alcohol (PVF) sponge with rBMCs, 2) PVF sponge with seeding of rBMCs: The PVF sponge after rBMCs seeding was removed from the bi-phasic scaffold before implantation, 3 ) Hydroxyapatite separated from rBMC seeded PVF sponge: Cylindrical porous hydroxyapatite separated from the bi-phasic scaffold after seeding of rBMCs in a PVF sponge, 4) PVF sponge with no rBMCs: Negative control ${ }^{\star *}$ vs. ${ }^{*}$ : N.S.

\section{Discussion}

It has been reported that bone regeneration can occur in the pores of a porous HA scaffold with rBMC seeding in vivo [15] and in vitro [16]. As described by Barry et al. [17], the desirable pore diameter for bone formation is $100-350 \mu \mathrm{m}$. However, it was reported in an in vivo histological examination that newly formed bone may be present mainly in pores in the peripheral regions and in only a few pores in the center area of the subcutaneously implanted porous columnar HA scaffolds containing rBMCs [9]. On the other hand, a cylindrical porous HA scaffold with a hollow center showed newly formed bone in many pores throughout all regions [9]. Interconnected pores in porous HA may act as a pathway for nutrition supply. However, the pores themselves would be blocked by newly formed bone, thus blocking the routes for neovascular infiltration for nutrient supply from outside of the scaffold into the pores in the internal area of the cylindrical porous HA. Cylindrical porous HA with a hollow center is an appropriate scaffold for bone formation promotion in the pores in the internal area [9]. The hollow center in the cylindrical porous HA scaffold may act as a major route for sufficient nutrition supply to form bone in the pores. A cylindrical porous HA scaffold with a hollow center may effectively promote bone formation.

Viable connective tissue can infiltrate into the hollow center of a cylindrical porous HA. The viability of the tissue in the hollow center must be maintained because it is the 
area in which dental pulp tissue would regenerate in the scaffold. If the viability of the infiltrated tissue in the hollow center of the bi-phasic scaffold cannot be maintained, the scaffold would be unsuitable for use as a tooth model for dental pulp reproduction. In this study as well as a previous study [18], necrotized tissue in the hollow center of the cylindrical porous HA was observed in the histological examinations. The hollow center of the cylindrical porous HA was not narrow enough to supply efficient nutrition to the infiltrated tissue. The scaffold with infiltration of fibrous connective tissue in the hollow center may have been placed unstably during subcutaneous implantation. The infiltrated connective tissue itself should be severed at terminal parts of the hollow center. On the other hand, infiltrated fibrous connective tissue in the sponge in the hollow center of the bi-phasic scaffolds remained viable. This may be because the stability of the connective tissue in the infiltrated fine filamentous construction of the PVF sponge can be maintained.

In the bi-phasic scaffolds in this study, bone was formed conspicuously in the sponge with rBMC seeding and in the surrounding cylindrical porous HA. The cells may have migrated into the HA from the sponge in the hollow center of the bi-phasic scaffold. The cylindrical porous HA was hypothesized to function as a barrier that held the rBMCs in place in the sponge and promoted their proliferation. In this study, we found a characteristic advantage of the sponge inserted into the hollow center of the cylindrical porous HA. In the bi-phasic scaffold investigated in this study, infiltrated viable connective tissue and newly formed bone was observed in the sponge in the hollow center. The fiber of the sponge may thus be suitable as a site for connective tissue to infiltrate and proliferate. Sponge should be inserted into the hollow center to prevent tissue necrosis.

The histological examination of the formaldehyde-acetalized PVF sponge implanted in subcutaneous tissue demonstrated that this sponge is superior in terms of biocompatibility. However, the PVF sponges are non-biodegradable, as previously reported [13] [19] [20]. These sponges were developed 60 years ago and used as a filling material for soft defects [21]. Recently, in an in vitro experiment on osteogenic responses using a PVF sponge, similar to our previous studies, it was reported that PVF sponges were useful as a new scaffold for bone tissue engineering [22]. If the sponge in a scaffold was biodegradable and absorbed promptly before bone formation, the material would be unable to function as a scaffold for bone formation. Indeed, the purpose of using a scaffold for tissue engineering is to maintain the configuration of regenerated tissue as a three-dimensional structure. A non-biodegradable sponge would remain structurally intact as a scaffold. The structural dissolution of the component inserted into the hollow center of the bi-phasic scaffold is one factor that may influence the experimental results. In the near future, biodegradable sponges will be applied in the hollow center of bi-phasic scaffolds for regeneration of tooth-pulp-like tissue.

No bone was observed in the PVF sponges with rBMCs that were separated from the bi-phasic scaffold before subcutaneous implantation. This may be because rBMCs, having been seeded in the sponge, were able to flow out in the tissue fluid. The sponge 
implanted in the rat dorsal subcutaneous tissue was under constant pressure and, as a result, seeded cells may have been extruded from the sponge into the surrounding tissue. Previous studies reported that bone formation was difficult in rBMC-seeded PVF sponges [23] [24]. The results of this study are supported by these reports. No bone formation by rBMCs in the PVF sponge observed in this study indicated that rBMCs could not adhere to the fine filamentous construction of the PVF sponge. However, bone was formed in the PVF sponge by rBMCs in the bi-phasic scaffold. A bi-phasic scaffold consisting of a cylindrical porous HA and PVF sponge was demonstrated as superior to a cylindrical porous HA scaffold that was previously used for the induction of bone [25]. The effects on bone formation of the bi-phasic scaffold were confirmed in the rMBC-seeded PVF sponge. The cylindrical porous HA as the outer layer of the bi-phasic scaffold seemed to inhibit the migration of rBMCs from the sponge into the tissue around the bi-phasic scaffold. The rBMCs in the sponge may have remained in the cylindrical porous HA, leading to bone formation in the sponge. Seeded rBMCs in the PVF sponge in the bi-phasic scaffold may have flown out from the sponge in the tissue fluid and reached the pores in the porous HA as the outer layer of the scaffold. The high adhesion of the rBMCs to the pores of HA was clearly demonstrated. The cylindrical porous HA component of the bi-phase scaffold may function as a barrier that inhibits the outflow of seeded rBMCs from the sponge. It was also observed in the histological examination that bone was not formed in the entire sponge. This suggests that the adhesiveness of the PVF sponge for rBMCs was poor. These results coincide with the description by Yoshikawa et al. [14]. One advantage of a bi-phasic scaffold with a hollow center is the ability to remove, renew or change the inserted material. After removal of the sponge from the hollow center in the bi-phasic scaffold, a new sponge containing different cells can be placed without difficulty. Seeded cells different from the ones in the material being inserted in the hollow center and in the outer layer could induce regeneration of tissue or an organ with a multilayer structure such as teeth.

It is anticipated that teeth will be created in the future from induced pluripotent stem cells. An extracted tooth germ is stored until use and the tooth grown from this germ by culture is transplanted into the defective portion of the tooth [26]. It was also reported that pulp was regenerated in a tooth root canal in which dental pulp had been lost [27] [28] [29]. However, considerable time is needed for tooth regeneration using induced pluripotent stem cells for clinical use. Also, extraction of the tooth germ causes surgical stress in young patients. Although these factors have yet to be resolved, the clinical application of regenerated dental pulp or regenerated teeth for this purpose is greatly anticipated. Future studies are required for achieving clinical applications of regenerated dental pulp or teeth.

In the bi-phasic scaffold evaluated in this study, the proliferation of connective tissue and small blood vessels was observed in the sponge. After bone formation in the cylindrical porous HA by the seeding of rBMCs in the sponge, dental pulp may be replicated by the seeding of fibroblasts, hematopoietic stem cells and neuroblasts in the sponge. The proliferation of fibrous tissue from the alveolar bone should then occur to connect 
the surface of the cylindrical porous HA. This connective tissue may have the potential to act as a periodontal substitute. The use of this type of bi-phasic scaffold would allow regeneration of the dental pulp-dentin complex with the ability to attach cells in cylindrical porous HA, and to receive two different kinds of cells in the cylindrical porous HA and PVF sponge. Dental pulp-dentin complex grown using the bi-phasic scaffold could be transplanted into a defect and normal mastication may be recovered.

\section{Conclusions}

Bone marrow cells are not able to adhere to a PVF sponge due to its fine filamentous construction. However, a bi-phasic scaffold composed of cylindrical porous HA with a PVF sponge showed a high level of osteocalcin and exhibited substantial bone formation. It was concluded from these results that this novel bi-phasic scaffold can contribute effectively to bone formation.

A bi-phasic scaffold composed of a cylindrical porous HA with a PVF sponge showed a high level of osteocalcin and exhibited substantial bone formation in the structure. It was concluded that this bi-phasic scaffold can contribute effectively to bone formation. Moreover, in the dual structure as a bi-phasic scaffold, the cylindrical porous HA could contribute as a barrier that held the rBMCs in place in the sponge and promoted their proliferation in it.

\section{Acknowledgements}

This study was performed in the Morphological Research Facilities, Biomaterials Research Facilities, Low-Temperature Facilities, Tissue Culture Facilities, Laboratory Animal Facilities and Photograph-Processing Facilities of the Institute of Dental Research, Osaka Dental University. This study was supported in part by 2012-2014 (C: 24592889), 2015-2017 (C: 15K11140) and 2016-2018 (C: 16K11574) Grants-in-Aid for Scientific Research (C) from the Japan Society for the Promotion of Science.

\section{References}

[1] Denrya, I. and Kelly, J.R. (2010) State of the Art of Zirconia for Dental Applications. Dental Materials, 24, 299-307. http://dx.doi.org/10.1016/j.dental.2007.05.007

[2] Osman, R.B. and Swain, M.V. (2015) A Critical Review of Dental Implant Materials with an Emphasis on Titanium versus Zirconia, Materials, 8, 932-958. http://dx.doi.org/10.3390/ma8030932

[3] Zhang, W., Walboomers, X.F., van Osch, G.J., van den Dolder, J. and Jansen, J.A. (2008) Hard Tissue Formation in a Porous HA/TCP Ceramic Scaffold Loaded with Stromal Cells Derived from Dental Pulp and Bone Marrow. Tissue Engineering: Part A, 14, 285-294. http://dx.doi.org/10.1089/tea.2007.0146

[4] Sopyan, I., Mel, M., Ramesh, S. and Khalid, K.A. (2007) Porous Hydroxyapatite for Artificial Bone Applications. Science and Technology of Advanced Materials, 8, 116-123. http://dx.doi.org/10.1016/j.stam.2006.11.017

[5] Oliveira, J.M., Silva, S.S., Malafaya, P.B., Rodrigues, M.T., Kotobuki, N., Hirose, M., Gomes M.E., Mano, J.F., Ohgushi, H. and Reis, R.L. (2009) Macroporous Hydroxyapatite Scaffolds for Bone Tissue Engineering Applications: Physicochemical Characterization and Assess- 
ment of Rat Bone Marrow Stromal Cell Viability. Journal of Biomedical Materials Research Part A, 91, 175-186. http://dx.doi.org/10.1002/jbm.a.32213

[6] Burastero, G., Scarfi, S., Ferraris, C., Fresia, C. and Sessarego, N., Fruscione, F., Monetti, F., Scarfò, F., Schupbach, P., Podestà, M., Grappiolo, G. and Zocchi, E. (2010) The Association of Human Mesenchymal Stem Cells with BMP-7 Improves Bone Regeneration of Critical-Size Segmental Bone Defects in Athymic Rats. Bone, 47, 117-126. 32213.

http://dx.doi.org/10.1016/j.bone.2010.03.023

[7] Thibault, R.A., Baggett, L.S., Mikos, A.G. and Kasper, F.K. (2010) Osteogenic Differentiation of Mesenchymal Stem Cells on Pregenerated Extracellular Matrix Scaffolds in the Absence of Osteogenic Cell Culture Supplements. Tissue Engineering. Part A, 16, 431-440. http://dx.doi.org/10.1089/ten.tea.2009.0583

[8] Dieudonne, F.X., Sévère, N., Biosse-Duplan, M., Weng, J.J., Su, Y. and Marie, P.J. (2013) Promotion of Osteoblast Differentiation in Mesenchymal Cells through Cbl-Mediated Control of STAT5 Activity. Stem Cells, 31, 1340-1349. http://dx.doi.org/10.1002/stem.1380

[9] Yoshikawa, M., Tsuji, N., Shimomura, Y., Hayashi, H. and Ohgushi, H. (2008) Osteogenesis Depending on Geometry of Porous Hydroxyapatite Scaffolds. Calcified Tissue International, 83, 139-145. http://dx.doi.org/10.1007/s00223-008-9157-y

[10] Yoshikawa, M., Shimomura, Y., Kakigi, H., Tsuji, N., Yabuuchi, T. and Hayashi, H. (2012) Effect of L-Lysine in Culture Medium on Nodule Formation by Bone Marrow Cells. Journal of Biomedical Science and Engineering, 5, 587-592. http://dx.doi.org/10.4236/jbise.2012.510072

[11] Yoshikawa, M., Kakigi, H., Yabuuchi, T. and Hayashi, H. (2014) Effects of Laminin on Hard Tissue Formation by Bone Marrow Cells in Vivo and in Vitro. Journal of Biomedical Science and Engineering, 7, 15-23. http://dx.doi.org/10.4236/jbise.2014.71003

[12] Kakigi, H., Yoshikawa, M. and Hayashi, H. (2012) Osteogenesis by Bone Marrow Cells in a Novel Hybrid Alginate/Calcium Phosphate Sponge Scaffold, Journal of Oral Tissue Engineering, 9, 113-125.

[13] Yoshikawa, M., Kakigi, H., Maeda, H., Nishikawa, I., Ikenaga, H., Inamoto, T. and Tsuji, N. (2015) Bone Formation in a Scaffold Composed of Cylindrical Hydroxyapatite and Tryptophan- or Lysine-Coated Sponge in Vivo. Journal of Biomedical Science and Engineering, 8, 389-398. http://dx.doi.org/10.4236/jbise.2015.86037

[14] Yoshikawa, M., Tsuji, N., Kakigi, H., Yabuuchi, T., Shimomura, Y., Hayashi, H. and Ohgushi, H. (2010) Dextran Coating on and among Fibers of Polymer Sponge Scaffold for Osteogenesis by Bone Marrow Cells in Vivo. Journal of Biomedical Science and Engineering, 3, 751-757. http://dx.doi.org/10.4236/jbise.2010.38100

[15] Guda, T., John, A., Walker, J.A., Pollot, B.E., Appleford, M.R., Oh, S., Ong, J.L. and Wenke, J.C. (2011) In Vivo Performance of Bilayer Hydroxyapatite Scaffolds for Bone Tissue Regeneration in the Rabbit Radius. Journal of Materials Science: Materials in Medicine, 22, 647-656. http://dx.doi.org/10.1007/s10856-011-4241-7

[16] Deplaine, H., Lebourg, M., Ripalda, P., Vidaurre, A., Sanz-Ramos, P., Mora, G., Prósper, F., Ochoa, I., Doblaré, M., Gómez, R, J.L., Izal-Azcárate, I. and Gallego, F.G. (2013) Biomimetic Hydroxyapatite Coating on Pore Walls Improves Osteointegration of Poly(L-lactic acid) Scaffolds. Journal of Biomedical Materials Research Part B: Applied Biomaterials, 101, 173-186. http://dx.doi.org/10.1002/jbm.b.32831

[17] Barry, J.J.A., Gidda, H.S., Scotchford, C.A. and Howdle, S.M. (2004) Porous Methacrylate Scaffolds: Supercritical Fluid Fabrication and In Vitro Chondrocyte Responses. Biomaterials, 25, 3559-3568. http://dx.doi.org/10.1016/j.biomaterials.2003.10.023

[18] Yoshikawa, M., Tsuji, N., Toda, T. and Ohgushi, H. (2007) Osteogenic Effect of Hyaluronic 
Acid Sodium Salt in the Pores of a Hydroxyapatite Scaffold. Materials Science and Engineering: C, 27, 220-226. http://dx.doi.org/10.1016/j.msec.2006.05.014

[19] Yoshikawa, M., Tsuji, N., Yabuuchi, T., Shimomura, Y., Kakigi, H., Hayashi, H. and Ohgushi, H. (2009) Osteogenesis by Dextran Coating on and among Fibers of a Polyvinyl Formal Sponge. International Journal of Medical, Health, Biomedical, Bioengineering and Pharmaceutical Engineering, 3, 89-93.

[20] Shi, J., Malcolm, M., Xing, Q. and Zhong, W. (2012) Development of Hydrogels and Biomimetic Regulators as Tissue Engineering Scaffolds. Membranes, 2, 70-90. http://dx.doi.org/10.3390/membranes2010070

[21] Schwartz, A.W. and Erich, J.B. (1960) Experimental Study of Polyvinyl-Formal (Ivalon) Sponge as a Substitute for Tissue. Plastic and Reconstrustive Surgery and Transplantation Bulletin, 25, 1-14. http://dx.doi.org/10.1097/00006534-196001000-00001

[22] Togami, W., Sei, A., Okada, T., Taniwaki, T., Fujimoto, T., Tahata, S., Nagamura, K., Nakanishi, Y. and Mizuta, H. (2014) Effects of the Water-Holding Capability of Polyvinyl Formal Sponges on Osteogenic Ability in In Vivo Experiments. Journal of Biomedical Materials Research Part B: Applied Biomaterials, 103, 188-194.

http://dx.doi.org/10.1002/jbm.b.33200

[23] Barr, C.E., Salley, J.J. and LeHew, R.A. (1964) Osteogenic Activity Following Bone and Sponge Implantation. Journal of Dental Research, 43, 26-34. http://dx.doi.org/10.1177/00220345640430011301

[24] Sinclair-Hall, A.H. (1964) Repair of Bony and Dentinal Defects Following Implantation of Polyvinyl Alcohol Sponge. Journal of Dental Research, 43, 476-494. http://dx.doi.org/10.1177/00220345640430040301

[25] Yabuuchi, T., Yoshikawa, M., Kakigi, H. and Hayashi, H. (2014) Hybrid Scaffolds Composed of Amino-Acid Coated Sponge and Hydroxyapatite for Hard Tissue Formation by Bone Marrow Cells. Journal of Biomedical Science and Engineering, 7, 316-329. http://dx.doi.org/10.4236/jbise.2014.76034

[26] Nakao, K. and Tsuji, T. (2008) Dental Regenerative Therapy: Stem Cell Transplantation and Bioengineered Tooth Replacement. Japanese Dental Science Review, 44, 70-75. http://dx.doi.org/10.1016/j.jdsr.2007.11.001

[27] Fouad, A.F. and Nosrat, A. (2013) Pulp Regeneration in Previously Infected Root Canal Space. Endodontic Topics, 28, 24-37. http://dx.doi.org/10.1111/etp.12039

[28] Rosa, V., Zhang, Z., Grande, R.H.M. and Nör, J.E. (2013) Dental Pulp Tissue Engineering in Full-Length Human Root Canals. Journal of Dental Research, 92, 970-975. http://dx.doi.org/10.1177/0022034513505772

[29] Schenk, U., Prenzel, H., Magnucki, G., Hoang-Vu, C., Schaller, H.G., Diederich, A., Gernhardt, C., Dietze, K., Navarrete Santos, A., Niehues, S.M., Jung, F. and Hiebl, B. (2015) Non-Autologous Endodontic Pulp Regeneration Approach in Molar Teeth of the Rat. Journal of Cellular Biotechnology, 1, 27-35. http://dx.doi.org/10.3233/JCB-15003 
Submit or recommend next manuscript to SCIRP and we will provide best service for you:

Accepting pre-submission inquiries through Email, Facebook, LinkedIn, Twitter, etc. A wide selection of journals (inclusive of 9 subjects, more than 200 journals)

Providing 24-hour high-quality service

User-friendly online submission system

Fair and swift peer-review system

Efficient typesetting and proofreading procedure

Display of the result of downloads and visits, as well as the number of cited articles

Maximum dissemination of your research work

Submit your manuscript at: http://papersubmission.scirp.org/

Or contact jbise@scirp.org 